Medicine Updates Faculty of medicine

October 2021,volume 7, issue 7 https://muj.journals.ekb.egdean@med.psu.edu.eg vice_dean_postgraduate@med.psu.edu.eg

DOI: 10.21608/muj.2021.93704.1057

ISSN : 2682-2741

Submitted: 31/8/2021

Accepted : 16/9/2021

Pages:25- 47

\title{
" Role of vitamin $E$ in modulating the effect of Streptozotocin-induced maternal diabetes on fetal liver development in albino rat "
}

\section{Authors}

\author{
Sarah Mohamed 曾 ${ }^{1}$; Noha Salem²; Hoda Hassan² ${ }^{2}$ Gamal Abdelrahman ${ }^{3}$ \\ ${ }^{1}$ Human anatomy and embryology, faculty of medicine,portsaid university, portsaid, Egypt \\ ${ }^{2}$ Anatomy and embryology department, faculty of medicine, Suez canal university, Ismailia, Egypt \\ ${ }^{3}$ Anatomy and embryology department faculty of medicine Suez canal university Ismailia Egypt
}

\section{Introduction}

Diabetes Mellitus (DM) is a chronic disease characterized by disorder in metabolism of fat, carbohydrate, and protein. Deficient secretion of insulin is translated into impaired carbohydrate (glucose) usage and hyperglycemia. DM considered being a major medical concern due to the high prevalence and the hazardous effects on patient's physical, mental and psychological states and the occurrence of morbidity (David, 2011).

World health organization (WHO) said that DM is one of the most common endocrine disorders in the world as the number of diabetics is expected to double by the year 2025 (Carvalho et al., 2009). It is suggested that over the next two decades, DM in the developing countries will be seen more in the young age group ranging from 20 to 45 years (Wild et al., 2010).

WHO Eastern Mediterranean Region stated that prevalence of DM would be increased by the following figures: 
- Number of population in Egypt for example that was diabetic in 2000 equals 2,623,000 and by 2030 the number expected will be 6,726,000 (Gardner and shoback, 2011).

Gestational diabetes (GDM) is a state in which women exhibits high glucose level in blood during the third trimester of pregnancy without previously history of diabetes mellitus. It begins when hormones from the placenta make the mother insulin resistant. It occurs in about 3-10\% of all pregnancies and the condition may disappear after labor (Thomas, 2005).

During pregnancy, several hormonal changes can result in some degree of glucose intolerance resulting in elevated sugar level in blood than normal, but still not high enough to be diagnosed as diabetes. During the third trimester of pregnancy, placenta produces hormones, which resist the actions of insulin. Usually, pancreas is capaable of producing more insulin (about three times more than the normal) to overcome the effect of the hormones of pregnancy on blood glucose level. Gestational diabetes developed when pancreas failed to produce enough amount of insulin, as the blood glucose level increased. (Carr et al., 2008).

Regulation of glucose uptake from the blood to most cells is mediated by insulin. Therefore, lake of insulin or insensitivity of its receptors has a main role in all types of diabetes. (Gardner and Shoback, 2011).

When the blood glucose level raises above the renal threshold, re-absorption of glucose in the proximal renal tubules will decrease, and part of the glucose remains in the urine (glycosuria). This increases the osmotic pressure of the urine and decreases re-absorption of water causing increased urine production (polyuria) and water loss. This loss is replaced osmotically from water present inside the cells causing dehydration and thirst (Bluestone, 2010).

Diabetes may result in hepatic diseases including steatosis, deposition of glycogen, nonalcoholic steatohepatitis (NASH), fibrosis, and cirrhosis. In $80 \%$ of diabetic patients, increased glycogen accumulation is present. Impaired glycogen synthesis in diabetes is a result of defective activation of glycogen synthase (Stone and VanThiel, 2005).

Liver is an important organ having a critical action in adjustment of carbohydrate metabolism. It is essential in maintenance of blood glucose levels and in providing continuous source of glucose to organs for energy. This role of liver in glucose homeostasis explains the pathogenesis of glucose imbalance in different liver diseases and give little vision about the mechanisms by which diabetes mellitus cause liver damage. (Mann et al., 2012). 
Steatosis, which is an abnormal accumulation of fat inside the liver, may be microvesicular or macrovesicular and may develop to fibrosis and cirrhosis. The major presenting signs is hepatomegaly with normal or slightly abnormal liver enzymes and normal levels of bilirubin (Silverman et al., 2010).

Increased incidence of cirrhosis can develop in diabetics as a result of progressive steatohepatitis, pericentral hepatic fibrosis and central hyaline sclerosis (Hano, 2008).

On histopathological level, liver is affected seriously. There is disaarangement of hepatocytes losing their characteristic concentric arrangement. Blood sinusoids and portal vessels are dilated and congested with mild centrilobular hepatocyte degeneration. Portal tracts show inflammatory infiltrate which caused destruction of some intrahepatic bile ducts mostly the smaller (interlobular and septal) ducts. There is an aggregation of lipid droplets in the hepatocytes cytoplasm (Zafar et al., 2009).

Streptozotocin is approved by Food and Drug Administration (FDA) for treating metastatic cancer of the pancreatic islet cells. Because of its high toxicity to beta cells, it has also been long used for inducing insulitis and diabetes on experimental animals (Merzouk et al., 2005). The mechanism of STZ to induce diabetes is by inducing irreversible damage to the pancreatic Beta cells and causing degranulation and the capacity to secrete insulin was lost. (Magee \& Swann, 2006)

Vitamin E has various biological functions; including antioxidant activity, gene expression, enzymatic activities, and neurological functions (Zingg et al., 2004). Vitamin E reacts with the free radicals and form a tocopheryl radical, which is reduced by a hydrogen donor such as vitamin C. As it is fat-soluble, it is integrated into cell membranes protecting them from oxidative damage. (Traber et al., 2011)

\section{Material and methods:}

This work was carried out in Anatomy department, Faculty of medicine, Suez Canal University.

Animals:

Fifteen virgin female albino rats, 150-250 grams in weight, were utilized throughout this work. They were purchased from anatomy department, Faculty of veterinary, Zagazig University. All animals were housed in spacious wire mish cages, at room temperature, 
received water and food ad libitum and were left for two weeks to acclimatize to laboratory conditions before the experiment.

Experimental design:

After acclimatization period, the rats were randomly divided into 3 equal groups ( 5 rats each) as follows:

Control group:

Animals were injected intraperitoneally with citrate buffer alone ( $\mathrm{pH} 4.5)$ as a single dose of $0.2 \mathrm{ml} / 100$ grams body weight (Zafar et al., 2009).

\section{Streptozotocin treated group (STZ treated):}

Animals were subjected to induction of diabetes mellitus before pregnancy as follows: Animals were fasted overnight and diabetes mellitus was induced in the following morning by intraperitoneal injection of a single dose of streptozotocin (powder form, Sigma Aldrich Company, Egypt) (35mg / kg body weight) dissolved in 0.1 ML citrate buffer solution ( $\mathrm{pH} 4.5$ ) immediately before use (Zafar et al., 2009).

Animals were injected by $3 \mathrm{~cm}$ of $5 \%$ glucose solution for 3 successive days to avoid the initial drug induced hypoglycaemia. Random blood glucose levels were assessed by bionime glucometer (blood strip tests). Blood samples were obtained from tail vein by snipping the rat tail randomly along the vein (Naggar et al., 2002).

Diabetes was confirmed when blood sugar level was more than $250 \mathrm{mg} / \mathrm{dl}$ on the third day after streptozotocin injection.

\section{3- Vitamin E and Streptozotocin treated group (vit E + STZ treated):}

Induction of diabetes was done as in the second group (STZ treated group).

Once pregnancy was confirmed, pregnant rats were received a dietary dose of vitamin E via oral route (200mg/kg body weight daily) throughout the pregnancy (Arzu et al., 2008).

Breeding and Determination of pregnancy:

After the citrate buffer injection in control group and detection of diabetes mellitus in STZ treated and vitamin E + STZ treated groups; induction of pregnancy was occurred in all groups by leaving one male albino rat in a cage with two females and remained there over night. In the following morning, the male was returned to a separate cage. Pregnancy was determined by the existence of spermatozoa in the vaginal smears. This day was the first day of pregnancy (GD1).

\section{Experimental Evaluation:}

The pregnant rats were weighted and their random blood sugar were measured. 
The pregnant rats were sacrificed at 09:00 o'clock am ( \pm 30 minutes) on gestational day 20 by overdose of ether. Their abdomens were opened and the uterine horns were excised along the antimesometrial border to reveal the fetuses and embryonic membranes. Fetuses were obtained through incisions along the posterior surface of the membranes, counted and weighed. General fetal morphology was observed and recorded. All fetuses were sacrificed by decapitation. The abdominal wall of each fetus was opened and the organs were removed. Livers were collected, weighted and then prepared for histological and immunohistochemical analysis.

\section{Assessment of fetal growth parameters:}

Fetuses were weighted and their crown-rump length, head length and biparietal diameter were measured using a Dial caliper.

Biochemical evaluation:

Blood glucose level was assessed for the first time as initial reading, at the first day of pregnancy, after first week of pregnancy, after second week of pregnancy and at the day of scarification.

\section{Histological Examination:}

Liver sections were taken from fetuses immediately after scarification. Tissues were immediately fixed in $10 \%$ formalin, dehydrated and installed in paraffin blocks. Serial sections ( $4 \mu \mathrm{m}$ thick) prepared and stained with hematoxyline and eosin (H\&E) (Drury and Wallington, 1980) and Periodic acid chiff (PAS) (Schiff, 1966). Sections were studied using Olympus light microscope and the histopathological changes were recorded.

Immunohistochemical technique:

Immunohistochemical technique in all liver sections was carried out using caspase-3(Rat polyclonal Antibody, CPP32, Ab-4, Thermo, UK) that purchased from LIFESPAN (BIOSCIENCE) for detection of caspase-3 cells markers in liver tissue.

Immunohistochemical staining procedure for caspase-3:

All steps were done at room temperature with a humidified chamber. Staining dishes were used. Sufficient volumes of reagents applied to completely cover the section. After each step, suction was done to remove reagents. Drying of specimens between each steps was avoided.

Steps of staining were done as follow:

Formalin-fixed, paraffin-embedded $5 \mu \mathrm{m}$ tissue sections were deparaffinized with xylene, dehydrated in ethanol and incubated with $3 \%$ hydrogen peroxidase for $5 \mathrm{~min}$. Antigen retrieval (a method of recovering the antigenicity of tissue sections that has been masked by 
formalin fixation) was carried out on sections by incubation in $100 \mathrm{~mm}$ sodium citrate $(\mathrm{pH}$ 6.0) at $100^{\circ} \mathrm{C}$ for five minutes. Then, sections were treated with $0.3 \% \mathrm{H}_{2} \mathrm{O}_{2}$ in methanol for 30 min to eradicate endogenous peroxidase activity and then stained using the immunoperoxidase technique. Anti caspase-3 rat polyclonal antibody (1:100 dilutions) then diluted in phosphate buffered saline solution (PBS) containing normal rat serum and applied as primary antibodies at $4^{\circ} \mathrm{C}$. Biotinylated rat anti rat immunoglobulin was utilized as secondary antibody. Peroxidase-conjugated avidin was used at a dilution of 1:500.

Then sections incubated in 1-3 drops peroxidase substrate for $5 \mathrm{~min}$. until desired stain intensity developed. The sections controlled for staining by rinsing water. Finally, sections were rinsed, then incubated with $0.05 \%$ diaminobenzidine $0.15 \% \mathrm{H}_{2} \mathrm{O}_{2}$ and counterstained with $10 \%$ hematoxyline then examined using Olympus light microscope and the histopathological changes were recorded (Joseph and Burmer, 1995).

\section{Statistical analysis:}

Data were collected, revised and then edited using SPSS (statistical program for social science). Mean \pm Standard deviation were used for descriptive data. The one way analysis of variance (ANOVA) was used to statistically evaluate the results obtained from control and treated groups. $\mathrm{P}$ value $<0.05$ was considered statistically significant (Burton, 2002).

Data presentation:

Data was presented in the form of tables.

\section{Ethical Considerations:}

1. Animals were handled only by the investigator.

2. There was no interference except after complete anesthesia of the animal by ether.

3. Animals were maintained in manners that provide their physical comfort.

\section{Results:}

\section{1- Biochemical results:}

Table (1) showed the maternal random blood sugar levels throughout the experiment in all groups. The initial random blood sugar level (RBS) did not present significant difference between the groups. Whereas, RBS level of STZ treated and vitamin E+ STZ treated groups in the 1st day of gestation, revealed high significant increase compared to control group. Moreover, after the first and second weeks of gestation and at the day of scarification, RBS levels were high significantly increased in both STZ treated and vitamin 
E+ STZ treated groups compared to control group, while, vitamin E+ STZ treated group showed a high significant improvement compared to STZ treated group.

Table (1): Levels of maternal random blood sugar in control and other treated groups throughout the experiment

\begin{tabular}{|c|c|c|c|c|c|}
\hline \multirow{2}{*}{ Groups } & \multicolumn{5}{|c|}{$\begin{array}{c}\text { Maternal random blood sugar level (mg/dl) } \\
\text { Mean } \pm \text { SD }\end{array}$} \\
\hline & $\begin{array}{l}\begin{array}{l}\text { Initialreading } \\
\text { (before } \\
\text { pregnancy) }\end{array} \\
\text { pregnan }\end{array}$ & $\begin{array}{c}\text { In } 1^{\text {st }} \text { day } \\
\text { of } \\
\text { gestation }\end{array}$ & $\begin{array}{c}\text { After one } \\
\text { week of } \\
\text { gestation }\end{array}$ & $\begin{array}{l}\text { After two } \\
\text { week of } \\
\text { gestation }\end{array}$ & $\begin{array}{c}\text { Final } \\
\text { (scarification) }\end{array}$ \\
\hline Control & $84 \pm 15.5$ & $85 \pm 7$ & $82 \pm 9.8$ & $90.5 \pm 16$ & $88 \pm 7$ \\
\hline $\begin{array}{l}\text { STZ } \\
\text { treated }\end{array}$ & $88.5 \pm 21$ & $301 \pm 7.6 * a$ & $325 \pm 19.7 * a$ & $\overline{343.7 \pm 15 * a}$ & $342.7 \pm 11 * a$ \\
\hline $\begin{array}{l}\text { Vitamin } \\
\text { E+STZ } \\
\text { treated }\end{array}$ & $96.6 \pm 5.7$ & $309 \pm 9 * a$ & $251 \pm 21.5 * a b$ & $183 \pm 11 * a b$ & $141.6 \pm 10 * a b$ \\
\hline
\end{tabular}

ANOVA test

$* \mathrm{p}<0.05 \quad \mathrm{a}=$ compared to control group $\quad{ }^{\mathrm{b}}=$ compared to STZ treated group

\section{2- Fetal growth parameters:}

Growth parameters of fetus was examined by measuring body weight, crown-rump length (CRL), biparietal diameter (BPD) and head length in all groups (Tables 2).

Table (2): showed fetal growth parameters in all groups. The fetal body weight values in STZ treated group revealed significant increase compared to control and Vitamin E + STZ groups. Vitamin E + STZ treated group showed a significant decrease in fetal body weight compared to STZ treated group and showed a significant increase in fetal body weight compared to control group. Fetal crown-rump length, fetal head length and fetal biparietal diameter values in STZ treated group revealed significant increase in crown-rump length compared to control and Vitamin E + STZ group. Vitamin E+ STZ treated group revealed a significant decrease in fetal crown-rump length compared to STZ treated group to be near the value of control group. was high significantly increased in STZ treated group compared to control group. 
Table (2): Fetal growth parameters in control and other treated groups

\begin{tabular}{|l||l||l||l|l||}
\hline \hline Groups & $\begin{array}{l}\text { Fetal body } \\
\text { weight }(\mathrm{gm}) \\
\text { Mean } \pm \text { SD }\end{array}$ & $\begin{array}{l}\text { Fetal crown- } \\
\text { rump length } \\
(\mathrm{cm}) \text { Mean } \pm \text { SD }\end{array}$ & $\begin{array}{l}\text { Fetal head } \\
\text { length }(\mathrm{cm}) \\
\text { Mean } \pm \text { SD }\end{array}$ & $\begin{array}{l}\text { Fetal biparietal } \\
\text { diameter }(\mathrm{cm}) \\
\text { Mean } \pm \text { SD }\end{array}$ \\
\hline \hline Control & $1.89 \pm 0.33$ & $2.7 \pm 0.13$ & $0.79 \pm 0.07$ & $0.76 \pm 0.07$ \\
\hline \hline $\begin{array}{l}\text { STZ } \\
\text { treated }\end{array}$ & $3.56 \pm 0.55 * \mathrm{a}$ & $3.4 \pm 0.27 * \mathrm{a}$ & $0.92 \pm 0.13 * \mathrm{a}$ & $0.92 \pm 0.17 * \mathrm{a}$ \\
\hline $\begin{array}{l}\text { Vit.E + } \\
\text { STZ } \\
\text { treated }\end{array}$ & $2.33 \pm 0.20 * \mathrm{~b} * \mathrm{c}$ & $2.6 \pm 0.27 * \mathrm{~b}$ & $0.82 \pm 0.09 * \mathrm{~b}$ & $0.82 \pm 0.09 * \mathrm{~b}$ \\
\hline
\end{tabular}

ANOVA test:

$* \mathrm{p}<0.05 \mathrm{a}=$ compared to control group $\quad \mathrm{b}=$ compared to STZ treated group

\section{3-Liver histopathological changes:}

a- Haematoxylin and Eosin (H\&E) stained fetal liver sections:

1. Control group:

Sections of fetal liver showed hepatocytes scattered around the central vein. Hepatocytes were separated from each other by blood sinusoids filled with large number of hematopoietic cells (mostly lymphocytes) with the presence of nucleated red blood cells (Figure 1).

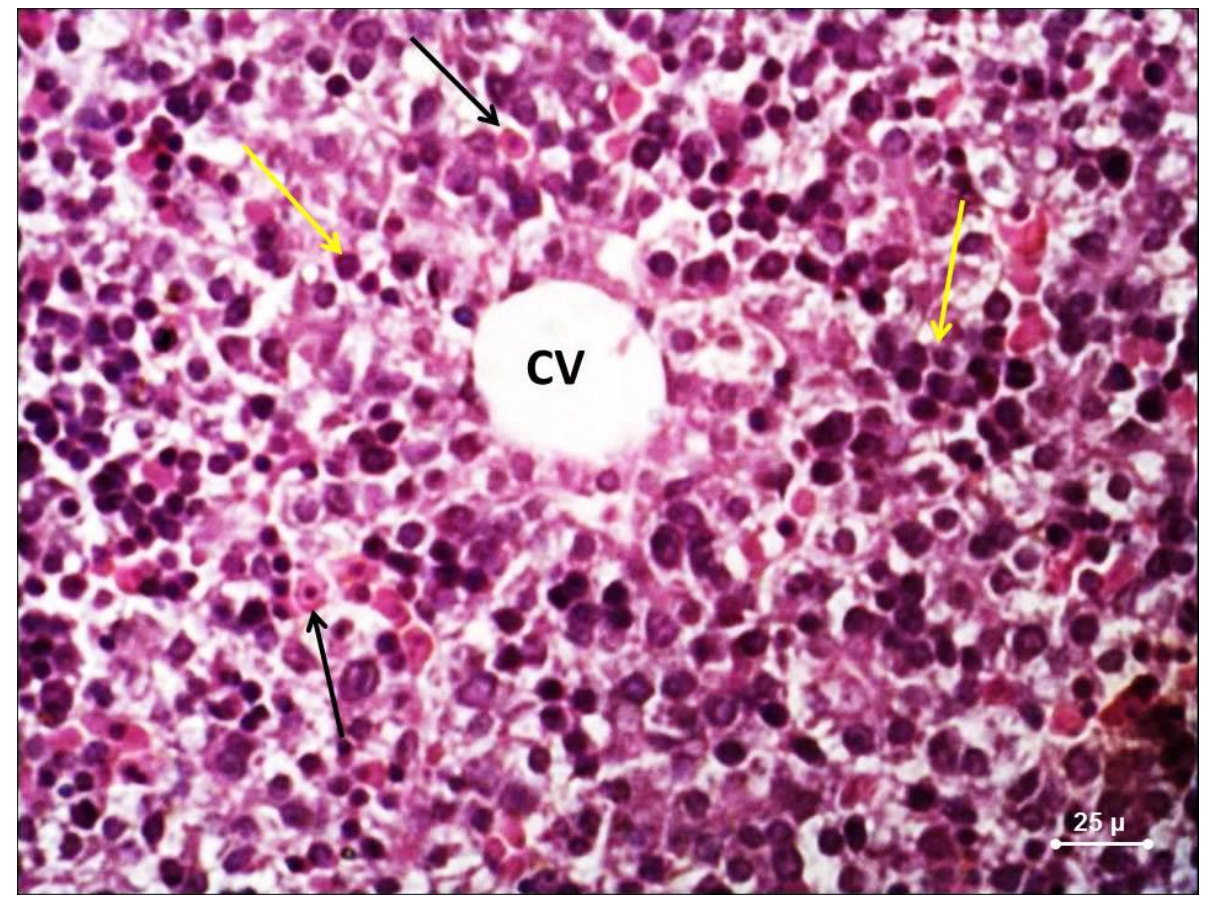

Fig. (1):A photomicrograph of fetal liver section in control group showing polyhedral shaped hepatocytes scattered around the central vein (CV). Hematopoietic cells, mostly lymphocytes (yellow arrow) in blood sinusoids. Nucleated red blood cells in the sinusoids (black arrow). $\mathrm{H} \& \mathrm{E} x 400$ 


\section{STZ treated group:}

Examination of the fetal liver in this group showed loss of cellular boundaries of hepatocytes with dispersed nuclei, hemorrhage with hemosiderin pigments deposition, dilated and congested central veins and sinusoids, vacuolar degenerations and areas of necrosis (Figure 2 7).

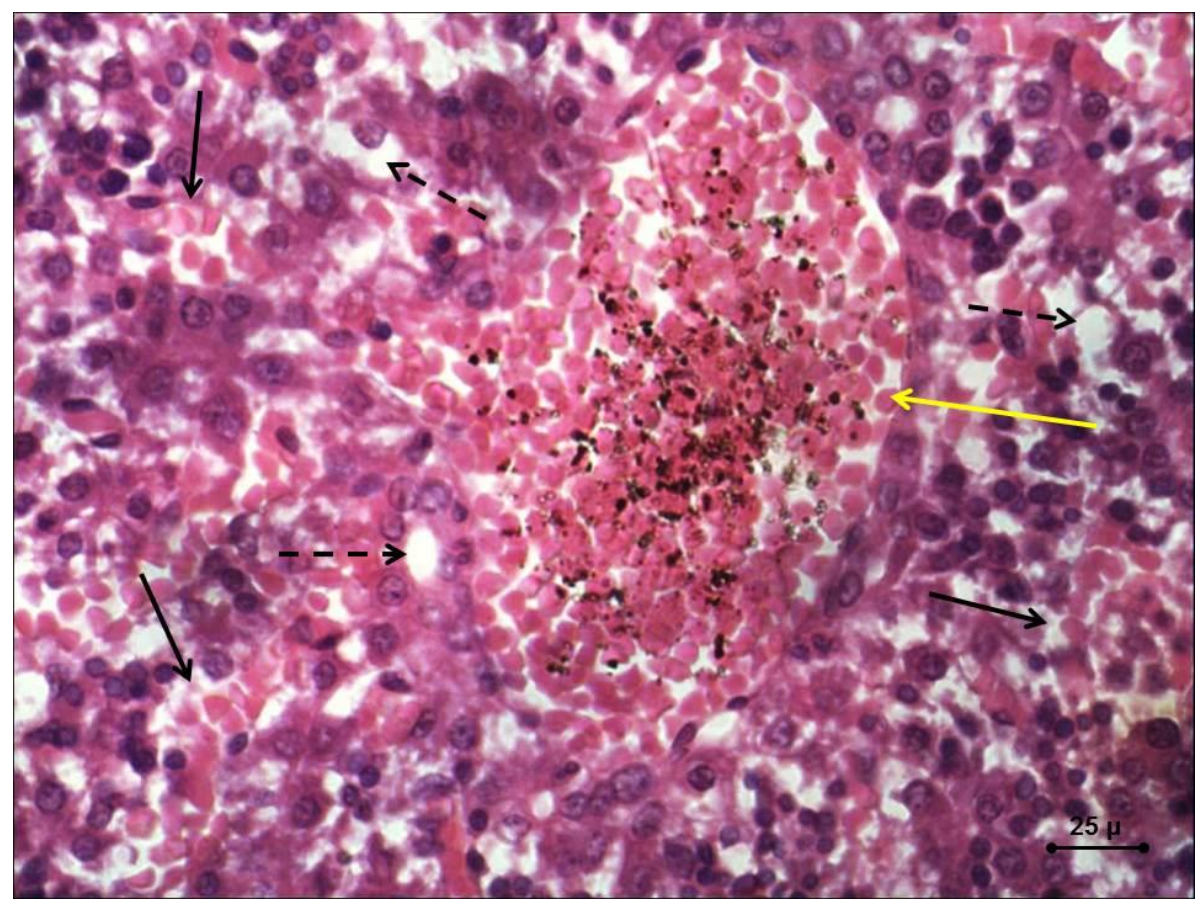

Fig. (2): A photomicrograph of fetal liver section in STZ treated group showing dilated congested central vein (yellow arrow) with hemosiderin pigments deposition, congested dilated sinusoids (black arrow) and vacuolar degeneration (dashed arrow). H\&E X400

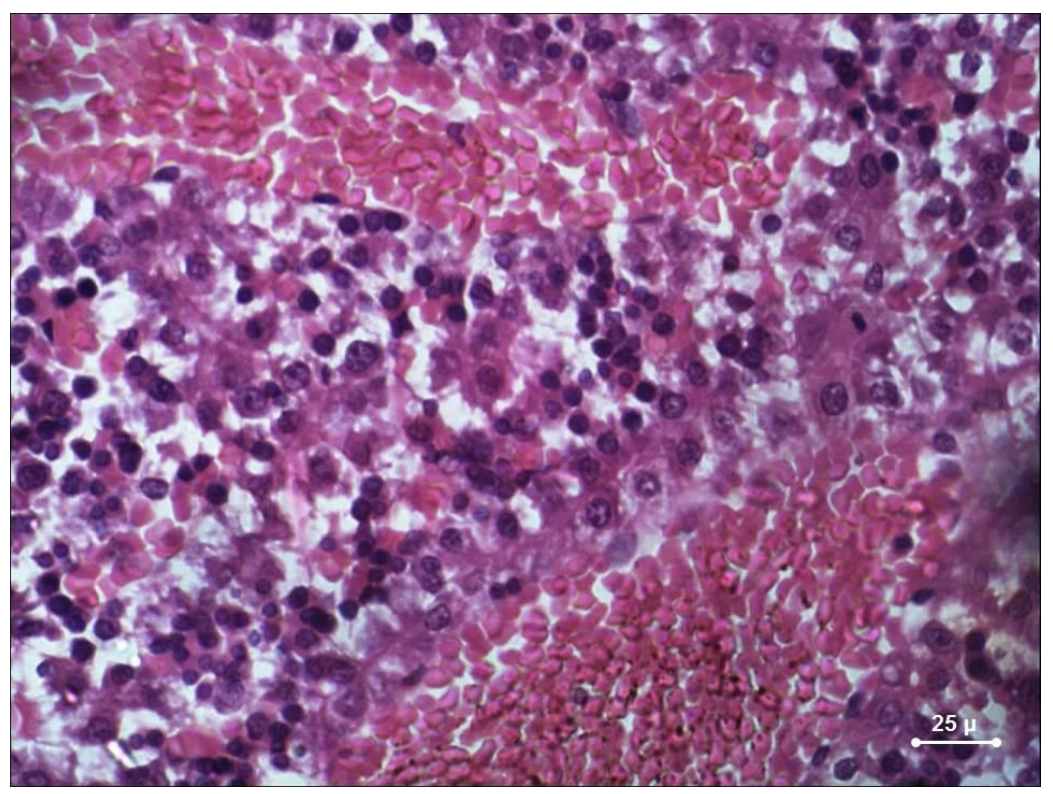

Fig. (3):A photomicrograph of fetal liver section in STZ treated group showing massive hemorrhage surrounded by necrotic cells. H\&E X400 


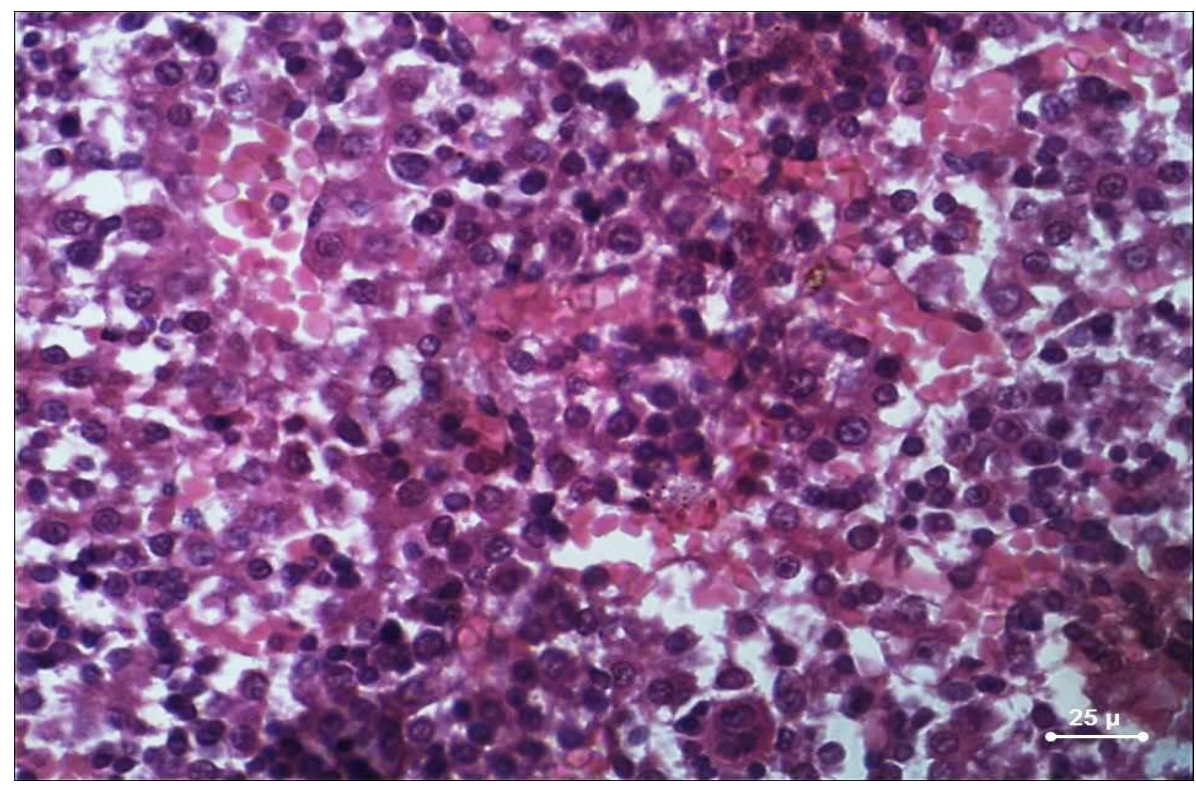

Fig. (4): A photomicrograph of fetal liver section in STZ treated group showing dilatation and congestion of sinusoids with massive hemorrhage. H\&E X400

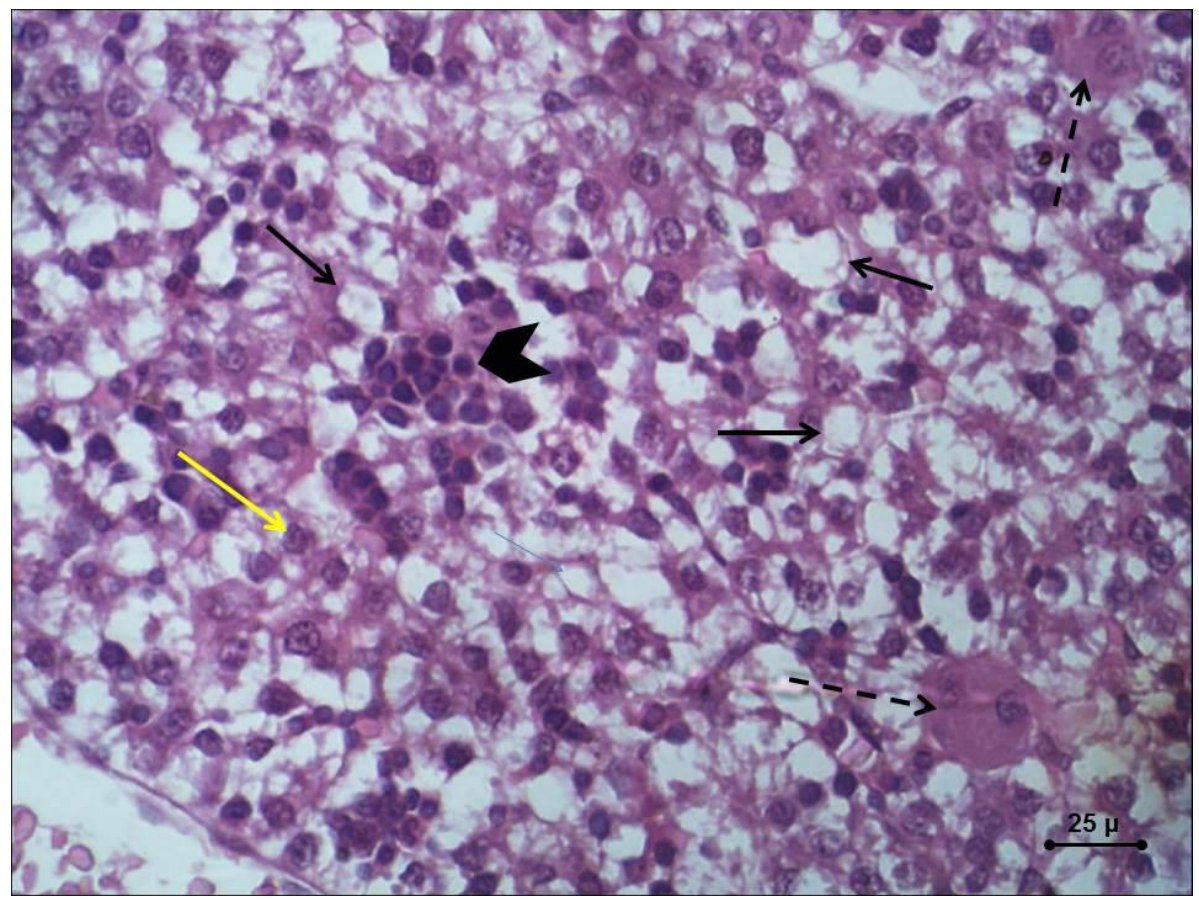

Fig. (5): A photomicrograph of fetal liver section in STZ treated group showing hepatocytes with ill-defined cellular boundaries (yellow arrow), vacuolar degeneration (black arrow), abundant lymphocytes (head arrow) and few 


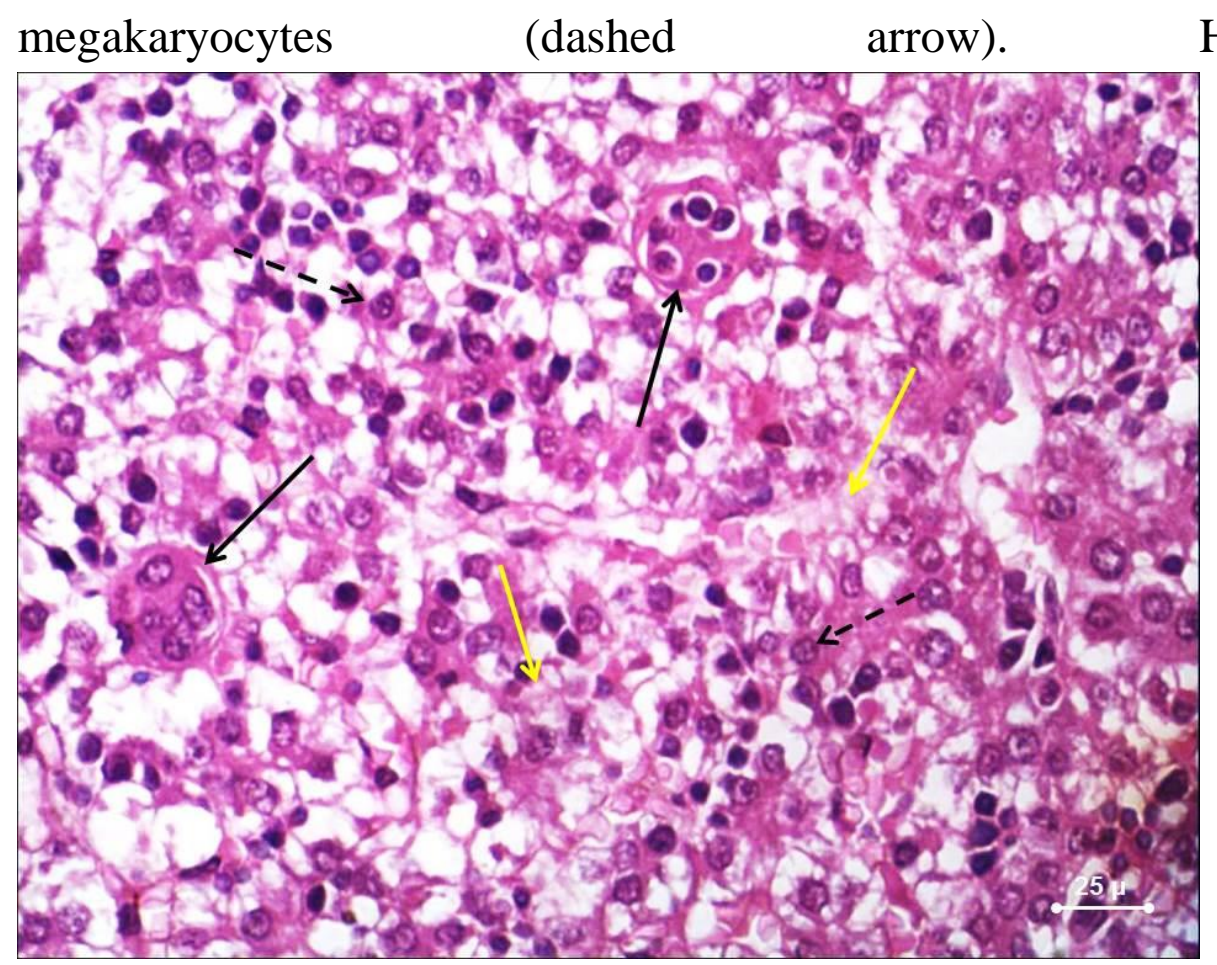

Fig. (6): A photomicrograph of fetal liver section in STZ treated group showing hepatocytes with ill-defined cellular boundaries and dispersed nuclei (dashed arrow). Areas of necrosis (yellow arrow), vacuolar degeneration, abundant lymphocytes, few megakaryocytes (black arrow) and dilated sinusoids. $\mathrm{H} \& \mathrm{E}$ X400

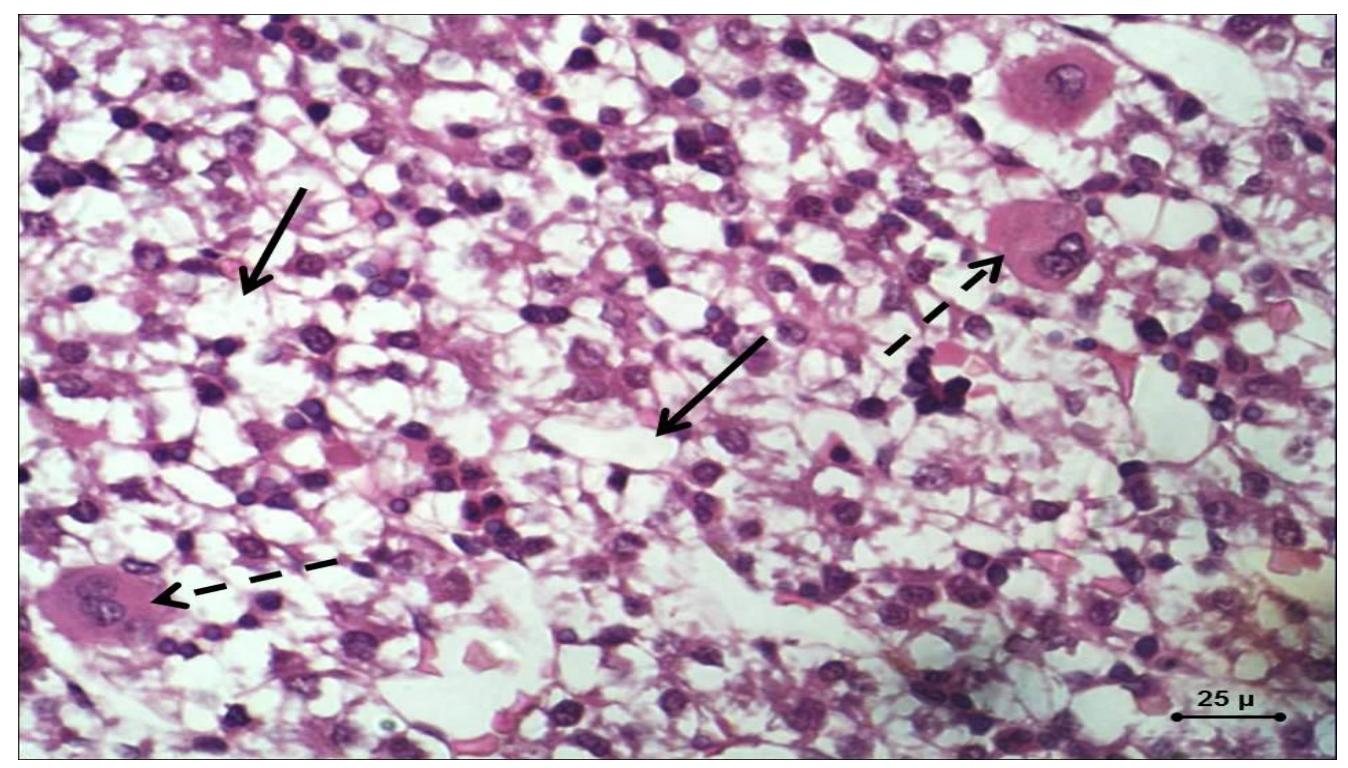

Fig. (7): A photomicrograph of fetal liver section in STZ treated group showing extensive vacuolar degeneration (black arrow) and megakaryocytosis (dashed arrow). H\&E X400 


\section{Vitamin E + STZ treated group:}

Most of the fetal liver sections showed central veins surrounded by intact hepatocytes, hematopoietic cells, slightly dilated and congested sinusoid with few areas of vacuolar degenerations (Figures 8 -11)

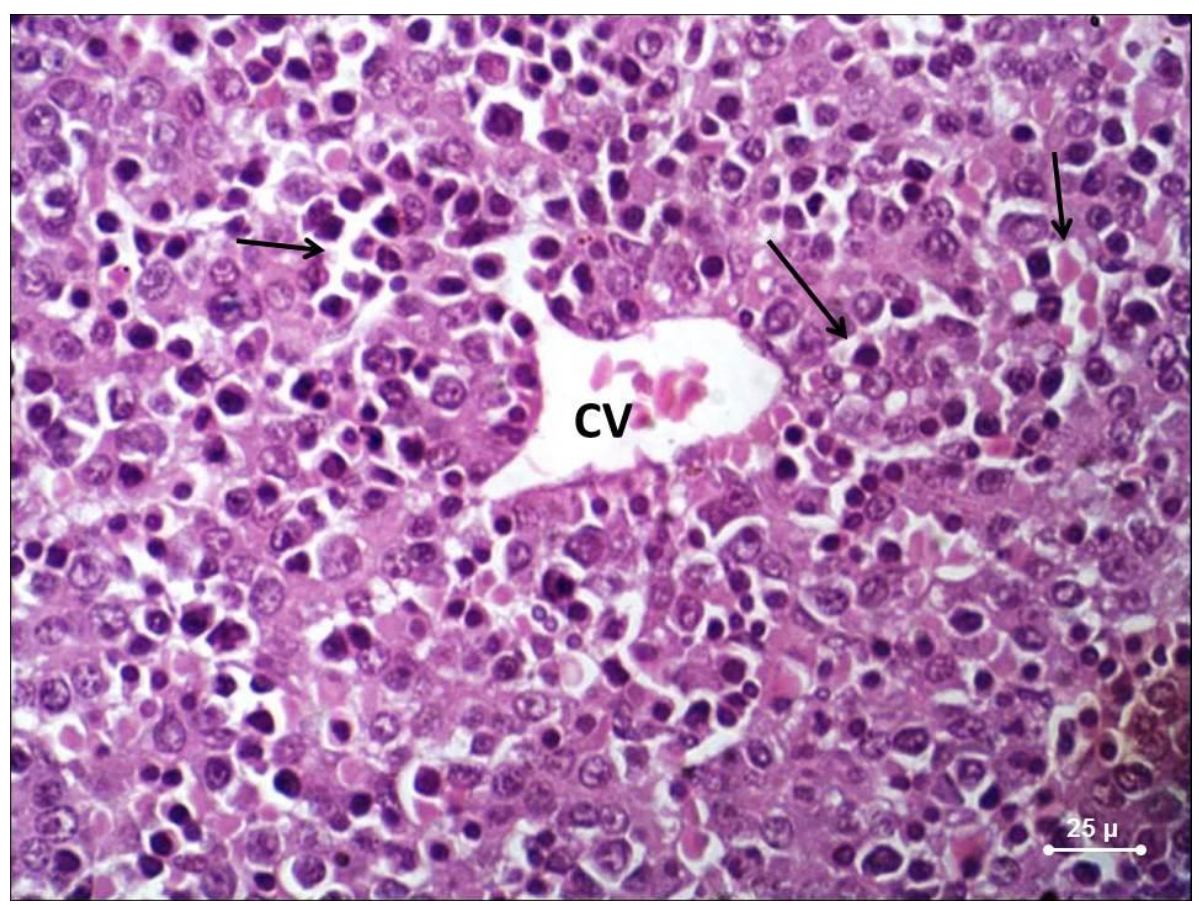

Fig. (8): A photomicrograph of fetal liver section in vitamin E + STZ treated group showing intact hepatocytes scattered surrounding the central vein $(\mathrm{CV})$ separated by sinusoids (arrow) filled with hematopoietic cells. H\&E x400

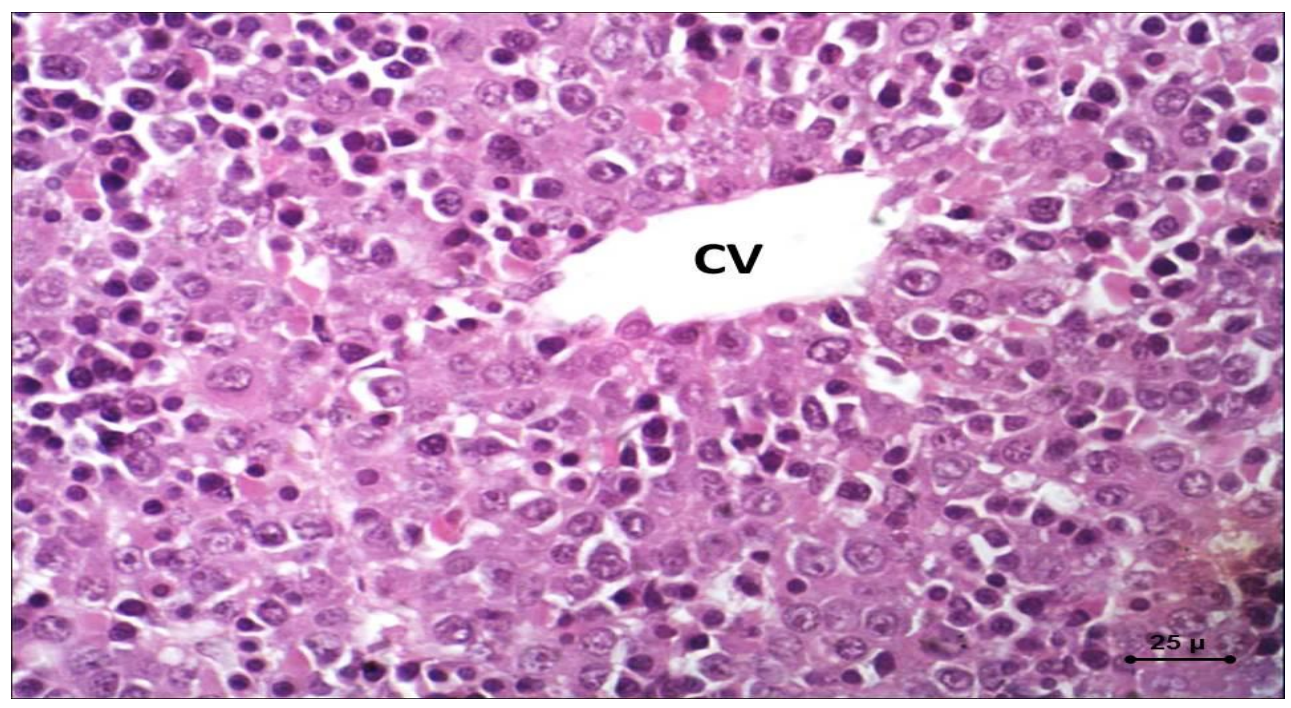

Fig. (9): A photomicrograph of fetal liver section in vitamin E + STZ treated group showing central vein $(\mathrm{CV})$ surrounded by intact hepatocytes separated by sinusoids filled with hematopoietic cells. H\&E x400 


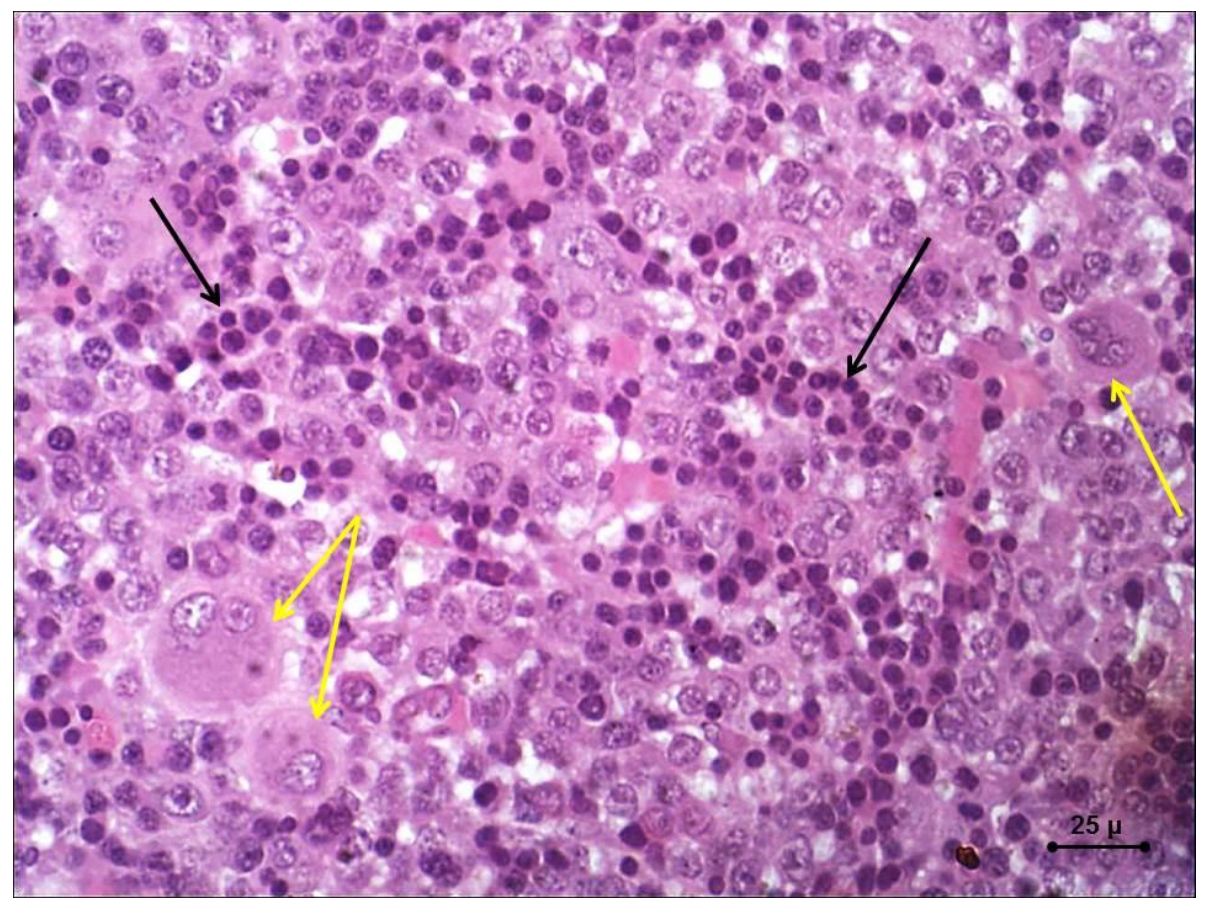

Fig. (10): A photomicrograph of fetal liver section in vitamin E + STZ treated group showing megakaryocytosis (yellow arrow) and slightly congested dilated sinusoids filled with red blood cells and lymphocytes (black arrow). H\&E x400

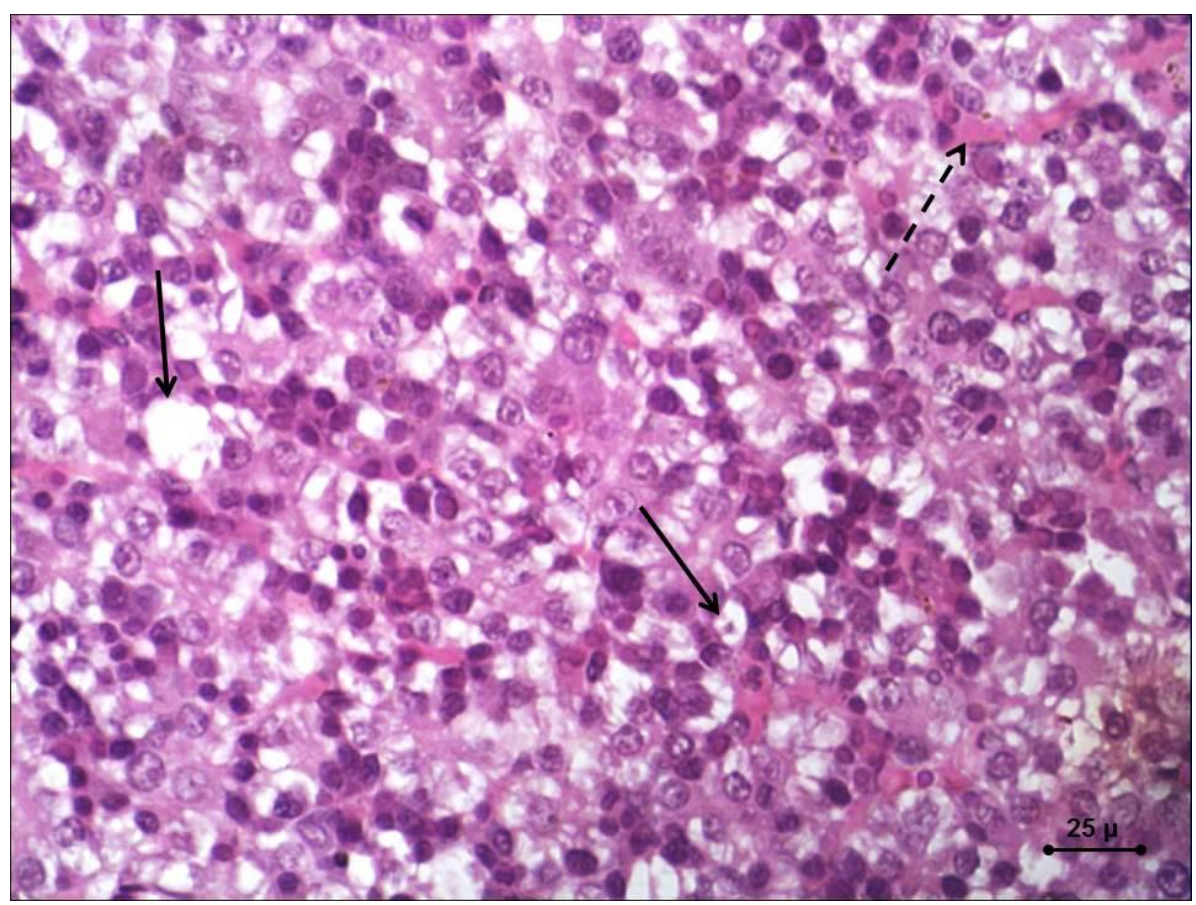

Fig. (11): A photomicrograph of fetal liver section in vitamin E + STZ treated group showing slightly congested sinusoids (dashed arrow) and vacuolar degeneration (arrow). H\&E x400 


\section{b- PAS stained fetal liver sections:}

\section{1- Control group:}

Fetal liver sections showed faint positively PAS stained hepatocytes with increased glycogen deposits surround the central vein (Figure 12).

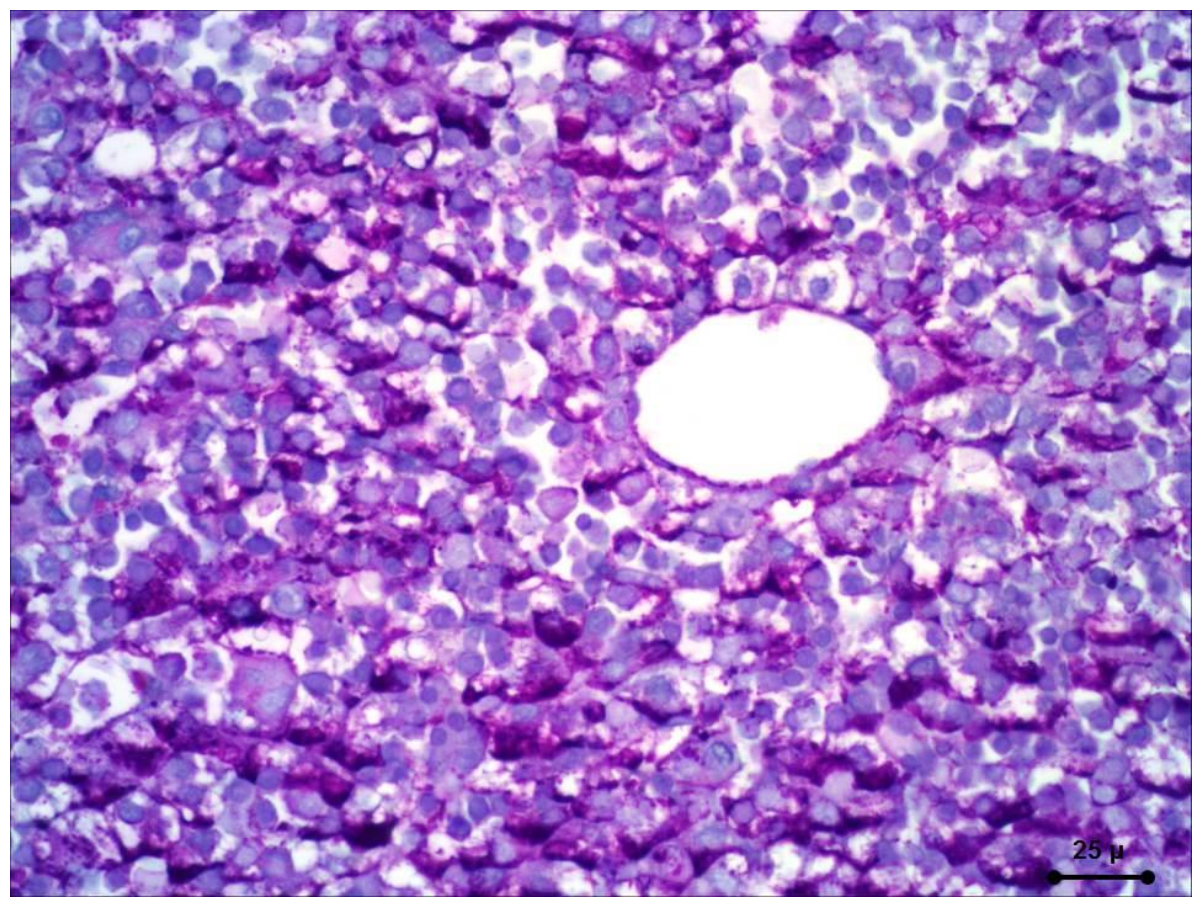

Fig. (12): A photomicrograph of fetal liver section in control group showing faint positively PAS stained hepatocytes with increased glycogen deposits around the central vein. PAS X400

\section{2- STZ treated group:}

Examination of fetal liver sections in this group showed deep positively PAS stained hepatocytes (Figure 13).

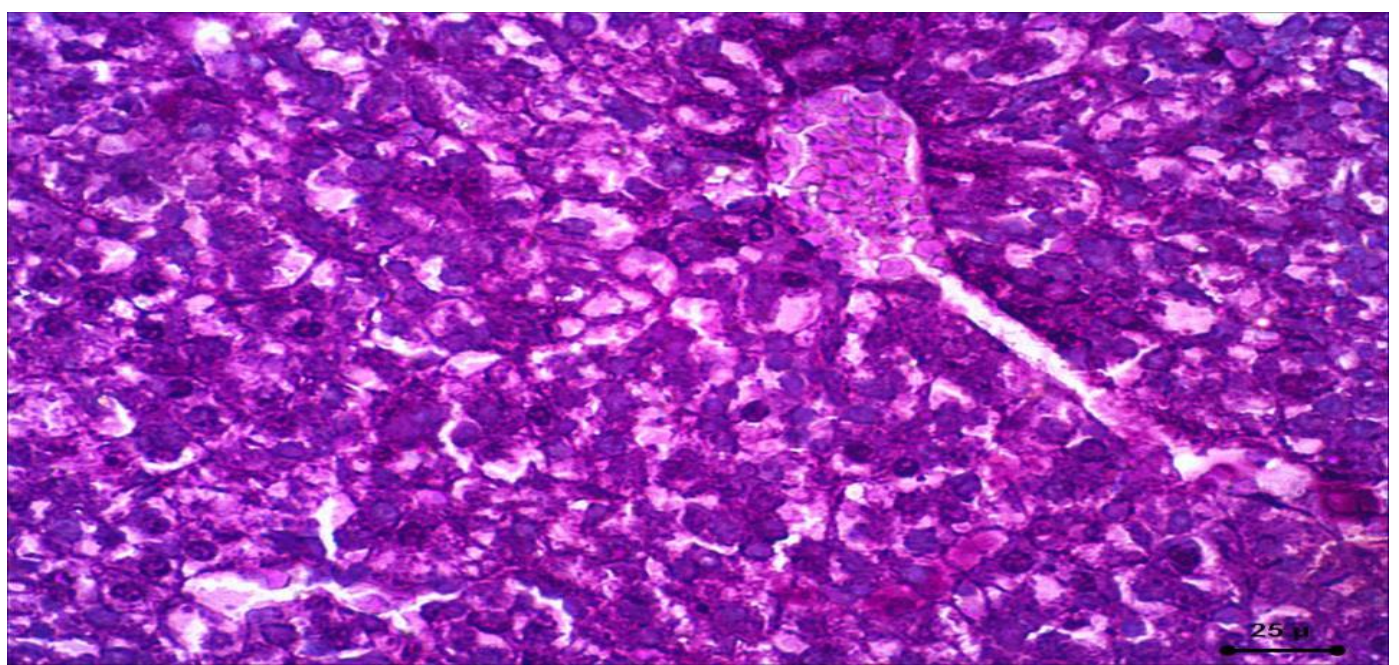


Fig. (13): A photomicrograph of fetal liver section in STZ treated group showing deep positively PAS stained hepatocytes. PAS X400

\section{3- Vitamin E +STZ treated group:}

Fetal liver sections in this group showed faint positively PAS stained hepatocytes (Figure 14).

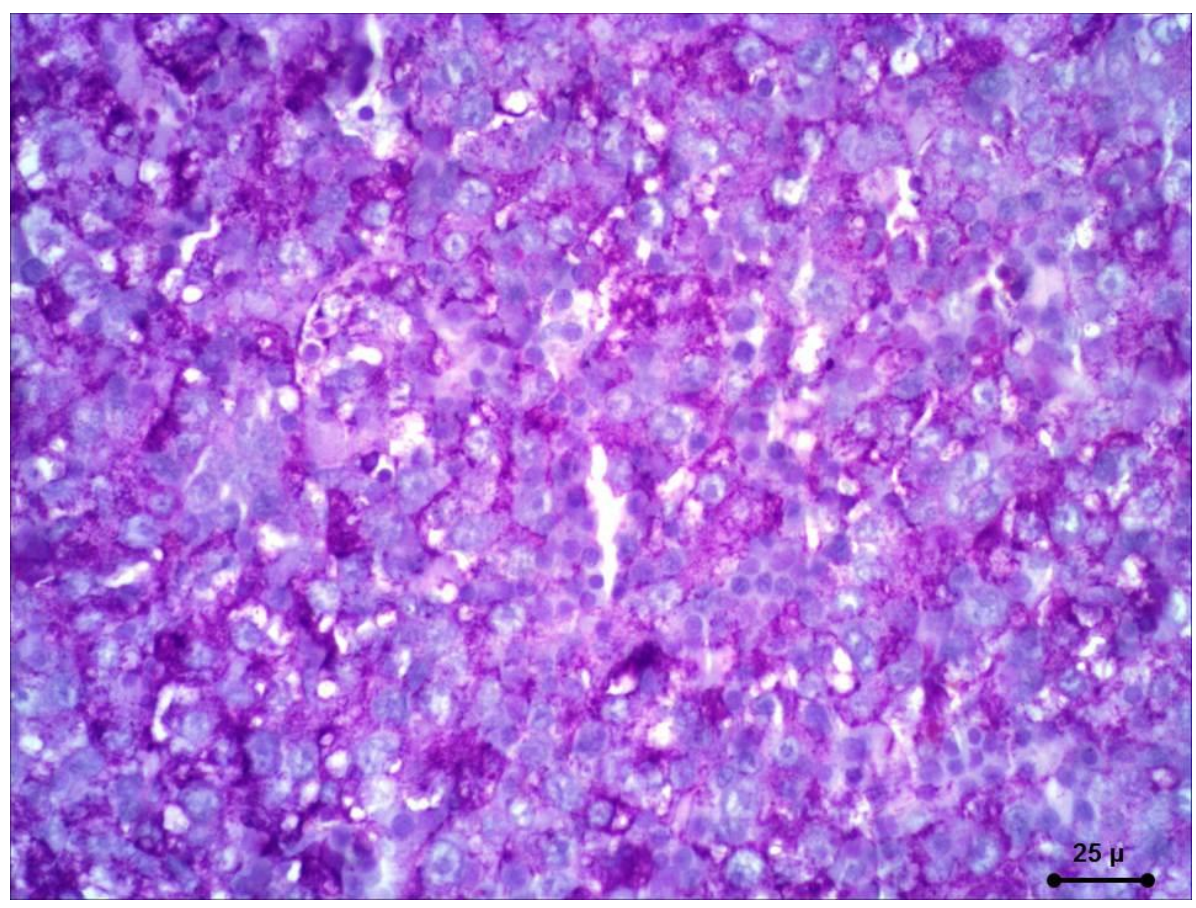

Fig. (14): A photomicrograph of fetal liver section in vitamin E+ STZ treated group showing faint positively PAS stained hepatocytes. PAS X400

\section{C- Caspase-3 immuno-stained liver sections:}

\section{Control group:}

Caspase-3 immunostaining of fetal liver sections in this group showed a negative cytoplasmic expression in $100 \%$ of specimens (Figure 15)

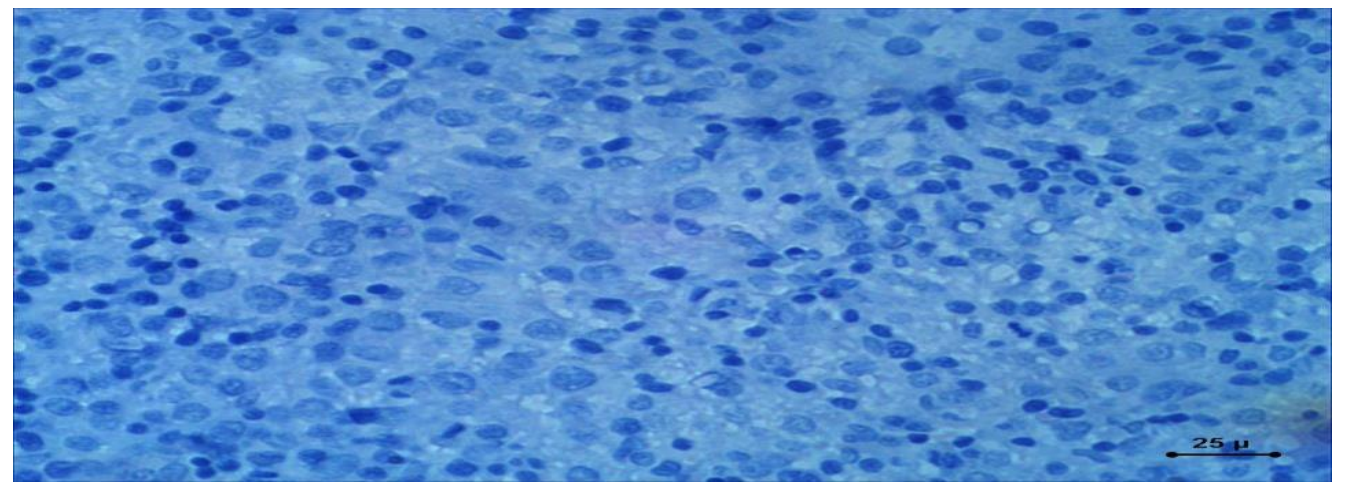


Fig. (15): A photomicrograph of fetal liver section in control group showing a negative Caspase-3 cytoplasmic immuno- expression. Caspase-3 immunostain X400

\section{STZ treated group:}

Fetal liver sections in this group showed an intense positive cytoplasmic caspase-3 immune-staining (Figure 16).

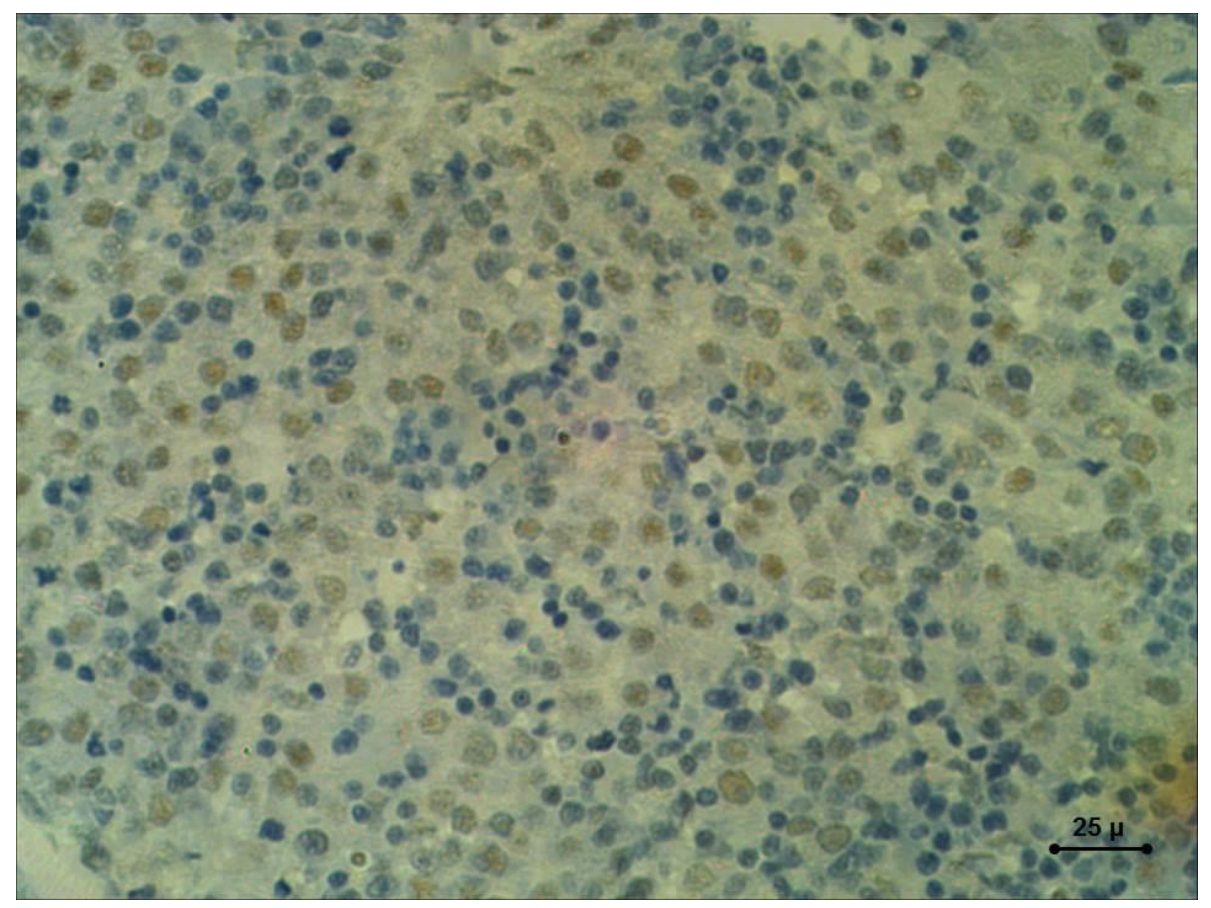

Fig. (16): A photomicrograph of fetal liver section in STZ treated group showing an intense positive Caspase-3 cytoplasmic expression. Caspase-3 immunostain $\mathrm{X} 400$

\section{Vitamin $\mathbf{E}+\mathrm{STZ}$ treated group:}

Caspase-3 immunostained fetal liver sections in this group showed a few traces of brownish cytoplasmic Caspase-3 immune-expression (Figure 17). 


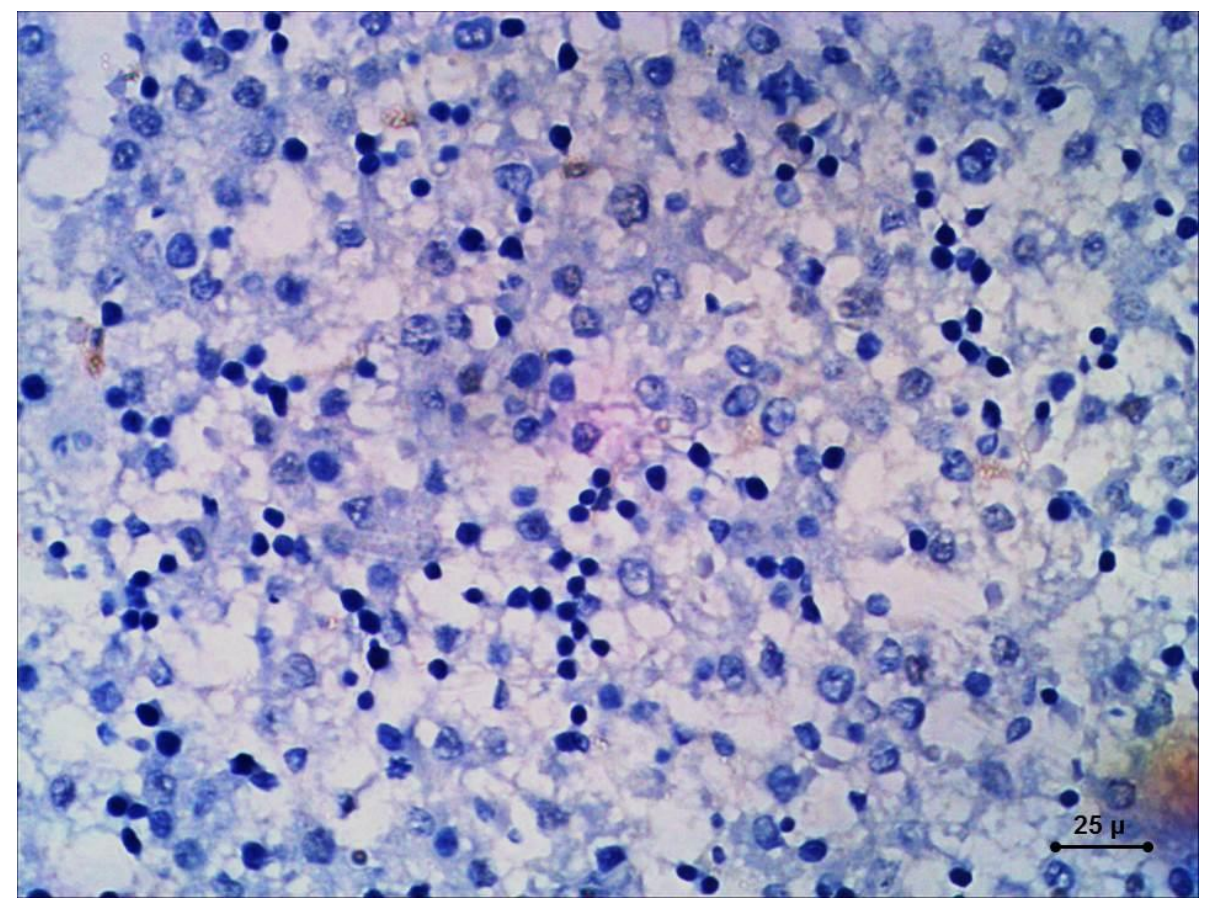

Fig. (17): A photomicrograph of fetal liver section in vitamin E+ STZ treated group showing very few traces of positive Caspase-3 cytoplasmic expression. Caspase-3 immunostain X400

\section{Discussion}

Streptozotocin, a glucosamine-nitrosourea compound gained from Streptomyces achromogenes, is used to produce insulin-dependent diabetes mellitus (IDDM) in animals. STZ causes toxic effects on $\beta$-cells in pancreas by interfering with glucose transporter GLUT-2 and causes DNA damage either by alkylation or peroxynitrite formation (Wang \& Gleichmann, 2008).

In our work, maternal blood glucose level in STZ group was significantly elevated after the first and second week of gestation and at day of sacrifaction. After administration of vitamin E random blood sugar (RBS) was noticed to be reduced all over the period of study showed high significant decrease compared to the diabetic group.

Our study was in agreement with Shirpoor et al., (2007) who revealed a significant reduction in blood glucose and glycated hemoglobin in diabetic rats 
treated with vitamin $\mathrm{E}(300 \mathrm{mg} / \mathrm{kg}$ body weight) compared with the untreated diabetics ones.

Luciana et al., (2009) used diabetic rats with STZ (35 mg/kg body weight) and vitamin E (2\%) exhibited a statistically significant decrease in glycemia and glycated hemoglobin compared to diabetic groups not treated with vitamin $\mathrm{E}$ proving the antioxidant activity of vitamin $\mathrm{E}$.

The mechanism of antioxidant to reduce levels of blood glucose has not been cleared. Belai et al., (1991) explained that antioxidants may increase metabolism of glucose in the peripheral tissues, resulting in reduction of plasma glucose levels.

Fetuses of diabetic mother showed significant increase in total body weight, crown-rump length, biparietal diameter and head length. In agreement of our study, Noor et al., (2013) examined fetuses of diabetic mothers and showed significant increase in weight of fetuses born to diabetic mothers in comparison with those of the control group. also, he said that there was no significant difference was observed in the length of fetuses of diabetic mothers when compared to the control ones, which was not in agreement with our study.

Our results revealed that histopathological examination of the fetal liver sections in diabetic group showed loss of cellular boundaries of hepatocytes with dispersed nuclei, hemorrhage with hemosiderin pigments deposition, dilated, congested central veins and sinusoids, vacuolar degenerations, areas of necrosis, abundant lymphocytes and megakaryocytosis.

In agreement with the current study, El-Sayyad et al., (2014), who used STZ as single intraperitoneal injection found that fetal liver of diabetic mother revealed degenerated hepatic architecture, major cell damage and massive vacuolation.

Noor et al., (2013) used STZ to induce diabetes in adult female rats. Fetal liver sections revealed enlarged hepatocytes, with many vacuolations in the cytoplasm. In some areas, hepatocytes had degenerated nucleus with marked 
dilated portal veins and hepatic sinusoids. There is accumulation of large amount of red and white blood cells inside the sinusoids and the perisinusoidal spaces. These changes are similar to what we found in our study.

Other studies showed histopathological changes similar to found in the current study. One of these studies, done by Sarah et al., (2009), was designed to assess the histological changes in liver of fetuses of mothers treated with Panax Ginseng root powder containing 3\% Ginsenosides and sections of fetal liver showed signs of degeneration, apparent in the sections were pale homogenous areas with dispersed nuclei. The heaptocytes did not exhibit cellular boundaries and the nuclei were seen to be dispersed. Congestion of the sinusoids was more pronounced and erythrocytes were accumulating in the lumen of the central vein as well as in the sinusoidal spaces.

In the present study fetal liver sections of diabetic mother revealed increased apoptosis as increased apoptic markers caspases 3 and that what El-Sayyad $\boldsymbol{e t}$ al., (2014) found in their study. They used STZ as single intraperitoneal injection to anticipate the development of hepatic lesions and impairment of function during fetal development. Their results exihibited that maternal diabetes and hypercholesterolemia predicted early hepatitis and apoptosis in mothers and their fetuses as a result of oxidative stress and increased apoptic markers caspases 3 .

Stirban et al., (2008) added that hyperglycemia leads to increase levels of intracellular $\mathrm{N}$-acetylglucosamine, which is one of the advanced glycated products, which are pro-inflammatory and activate PKC. This byproduct reacts with serine and threonine residues in transcription factors, resulting in pathologic alterations in gene expression. The final consequence of these pathological changes is increased inflammation and increased oxidative stress causing endothelial cell alterations in blood vessels.

Because of increased endothelial proliferation in capillaries, vascular permeability is increased. It is accompanied by destruction of the blood-tissue 
barrier allowing fluid accumulation in the deep tissues with resultant tissue damage. (Stirban et al., 2008)

Cheung et al., (2010) added that endothelial cell destruction induces dilatation of arterioles and increases capillary bed pressure resulting in formation of microaneurysm, leakage of vessel and rupture.

Conclusion:

Vitamin E can modulate the toxic effect of streptozotocin induced maternal diabetes on fetal liver structure in albino rats.

References:

1. Arzu S, Sava G, Oktay S, Sabiha C, Murat B, Murat U and Gulden B. Effects of vitamin E supplementation on oxidative stress in streptozotocin induced diabetic rats: investigation of liver and plasma. Yonsei Medical Journal. 2004; 45: 703-710.

2. Belai A, Lincoln J, Milner P and Burnstock G. Diferential effect of streptozotocin-induced diabetes on the innervation of the ileum and distal colon. Gastroenterology. 1991; 100:1024-1032.

3. Bernuau D, Guillot R, Durand-Schneider A, Poussier P, Moreau P and Feldmann G. Liver perisinsoidal fibrosis in BB rats with or without overt diabetes. Am J Pathol . 2005; 120: 38-45.

4. Bluestone J A, Herol, K and Eisenbarth G. Genetics, pathogenesis and clinical interventions in type 1 diabetes. Nature. 2010; 464 (7293): 1293-1300.

5. Burton R. Basic Statistical tests, Department of Biology, Alverno College. 2002.

6. Carr DB and Gabbe S. Gestational Diabetes: Detection, Management, and Implications. Clin Diabetes. 2008; 16(1): 4.

7. Carvalho EN, Carvalho NS and Ferreria LM. Experimental model of inductipn of diabetes mellitus in rats. Acta cir. Bras.2009; 18:60-64. 
8. Cheung N, Mitchell P and Wong TY. Diabetic Retinopathy. The Lancet. 2010; 376(9735):124-136.

9. David G. Gardner, Dolores (2011). Greenspan's basic \& clinical endocrinology ( $9^{\text {th }}$ ed.). New York: McGraw-Hill Medical. Chapter 17.

10.Drury R. and Wallington E, preparation and fixation of tissues, tissue processing, microtomy, general staining procedures, carbohydrates and mucosubstances and lipids carleton's Histological technique. 5th ed. New York: Oxford University Press, 1980; 36:239-241.

11.El-Sayyad HI, Al-Haggar MM, El-Ghawet HA and Bakr IH. Effect of maternal diabetes and hypercholesterolemia on fetal liver of albino Wistar rats. J. Nut. 2014; 30(3):326-36.

12.Gardner D, Shoback D. ÂGreenspan's basic \& clinical endocrinology ( $9^{\text {th }}$ Ed.)E. New York:McGraw-Hill Medical. 2011; 17:443-468.

13. Hano T. Pathohistological study on the liver cirrhosis in diabetes mellitus. Kobe J Med Sci. 2008; 14: 87-106.

14.Joseph B. and Burmer G. Lifespan bioscience inc., The immunohistochem Antibody Comp. 1995.

15.Luciana P, Renata VF, Eleandro A, Gabriela V, Célia R, Jacqueline N and Maria RM . Vitamin E ( $\alpha$-tocopherol) supplementation in diabetic rats: effects on the proximal colon. BMC Gastroenterology. 2009; 9:88.

16. Magee P N and Swann P F. Nitroso compounds. Br. Med. Bull. 2006; 25: 240-4.

17.Mann FC and Magath TB. Studies on the physiology of the liver. II. The effect of the removal of the liver on the blood sugar level. Arch Intern Med. 2012; 30:73-84.

18. Merzouk H, Madani S, Chabane S D, Prost J, Bouchenak, M and Belleville J. Time course of changes in serum glucose, insulin, lipids and tissue lipase activities in macrosomic offspring of rats with Streptozotocin induced diabetes. Clin. Sci. 2005; 98(1): 2130. 
19.Naggar H, Ola M, Moore P, Huang W, Bridges C, Ganapathy V and Smith S. Downregulation of the reduced-folate transporter by glucose in cultured retinal pigment epithelial cells and in streptozotocininduced diabetic mice. Invest. Ophthalmol. Vis. Sci. 2002; 43: 556-563

20.Noor A, Soad S, Nasra N and Saleh K. cellular changes in muscles and liver of macrosomic fetuses born to diabetes rats: histological and immunohistochemical study. Life Science Journal. 2013;10(2): 512523.3

21.Sarah K, Tahir M, Mumtaz F and Sami W. Histological changes in fetal liver after maternal treatment with panax ginseng. Biomedica. 2009; 25: 88-92.

22. Schiff U, Scheuer J and Chalk B. Special techniques of microscopy. Clinical tests histopathology. First ed. London: Wolf Medical Publications Ltd, 1966:40-100.

23. Shirpoor A, Ansari MHK, Salami S, Pakdel FG and Rasmi Y. Effect of vitamin $\mathrm{E}$ on oxidative stress status in small intestine of diabetic rat. World J Gastroenterol. 2007; 13:4340-4344.

24.Silverman JF, O'Brien KF, Long S, Leggett N, Khazanie PG, Pories WJ, Norris JR and Caro JF. Liver pathology in morbidly obese patients with and without diabetes. Am J Gastroenterol. 2010; 85:1349-55.

25.Stirban A, Rosen $\mathrm{P}$ and Tschoepe D. Complications of type 1 diabetes: new molecular findings. Mount Sinai Journal of Medicine.2008; 75(4):328-351.

26. Stone BE and VanThiel DH: Diabetes mellitus and the liver. Sem Liver Dis. $2005 ;$ 5:8-28.

27. Thomas R Moore, MD et al. Diabetes Mellitus and Pregnancy. $\underline{\operatorname{med} / 2349}$ at eMedicine. Version: Jan 27, 2005 update.

28. Traber MG, Maret $G$ and Stevens F. Free Radical Biology and Medicine - Vitamins C and E: Beneficial effects from a mechanistic 
perspective. Free Radical Biology and Medicine. 2011; 51 (5): 100013.

29. Wang $\mathrm{Z}$ and Gleichmann H. GLUT2 in pancreatic islets: crucial target molecule in diabetes induced with multiple low doses of streptozotocin in mice. Diabetes. 2008; 47 (1): 50-6.

30.Wild S, Roglic G, Green A, Sicree R and King H. Global prevalence of diabetes: estimates for the year 2000 and projections for 2030. Diabetes Care. 2010; 27: 1047-1053.

31.Zafar M, Naeem-ul-hassan S, Ahmed M and Kaimkhani ZA. Altered liver morphology and enzymes in streptozotocin induced diabeti rats. Int. J. Morphol. 2009; 27(3): 719-725. 